\title{
A Sewage Sludge Derived Composite Material for Adsorption of Antibiotics - Kinetics
}

\author{
Pengfei Zhang ${ }^{1}$, Rui Ding ${ }^{1}$, Mykola Seredych ${ }^{2}$, Teresa J. Bandosz ${ }^{2}$ \\ Department of Earth and Atmospheric Sciences, City College of New York, New York, USA \\ ${ }^{2}$ Department of Chemistry, City College of New York, New York, USA \\ Email: pzhang@sci.ccny.cuny.edu, tbandosz@sci.ccny.cuny.edu
}

Received 2012

\begin{abstract}
A novel sewage-sludge derived composite material was developed for the adsorptive removal of organic pollutants from water. In this study a batch adsorption study was carried out to examine the kinetics of antibiotics adsorption by this composite material. A pseudo-second order kinetics model fits the data extremely well, suggesting that chemical adsorption, rather than physical adsorption, is likely the main mechanism of the separation process.
\end{abstract}

Keywords: Sewage Sludge; Composite Material; Adsorption Kinetics; Antibiotics; Wastewater Treatment

\section{Introduction}

An estimated 100,000 to 200,000 tons of antibiotics are produced each year [1] as human and veterinary medicine [2,3], and as much as $30 \%$ to $90 \%$ of administered antibiotics can be excreted without being metabolized [4]. The excreted antibiotics are often discharged into surface waters or leached into soils and groundwater from manure-based fertilizers or sewage sludge [2, 5], contaminating aquatic and terrestrial environments. Even low concentration of antibiotics in the environment may lead to the development and spreading of antibiotic resistance. Therefore, there is an urgent need to develop advanced treatment technologies that can effectively remove antibiotics and other related pollutants from contaminated water, especially from drinking water sources.

In a recent study [6], we demonstrated that composite materials derived from the pyrolysis of sewage sludge and waste oil sludge were able to simultaneously remove a dozen or so antibiotics from water. The adsorption capacities of these composite materials are comparable to typical granular activated carbons [6,7]. Physical adsorption, reactive adsorption and specific polar interactions were indicated as the mechanisms of the separation process [6]. The objective of this study was to examine the kinetics of antibiotics adsorption by one of those sewage sludge derived composite materials.

\section{Materials and Methods}

\subsection{Composite Material}

The composite material (SSWO950) was obtained by pyrolysis of a mixture (50:50 ratio based on the wet mass) industrial waste oil sludge (WO) from Newport News Shipyard (Newport News, VA, USA) and dewatered sewage sludge (SS) from Wards Island Water Pollution Control Plant (New York, NY, USA), at $950{ }^{\circ} \mathrm{C}$ in a nitrogen atmosphere in a fixed bed (hori-

*Partially supported by the US Environmental Protection Agency. zontal furnace).

\subsection{Batch Adsorption Experiment}

Adsorption of a mixture of 11 antibiotics plus 2 anticonvulsants (see Table 1 for the list of compounds) was measured in closed batch systems at room temperature. One $\mathrm{mL}$ of the mixture solution (100 mg. $\mathrm{L}^{-1}$ of each compound) was mixed with 0.050 $\mathrm{g}$ of the SSWO950 material in amber glass vials. The sample vials were sealed and then shaken on an orbital shaker. Duplicate samples were taken at 2, 4, 6, 8, and 23.5 hours and analyzed for the kinetics study.

\subsection{Sample Analysis}

All samples were analyzed using liquid chromatography-tandem mass spectrometry (LC/MS/MS) with electron spray ionization (ESI) and multiple reaction monitoring (MRM). Details of the analysis can be found in Ding et al. [6].

Table 1. Antibiotics and anticonvulsants tested in this study.

\begin{tabular}{ccc}
\hline Category & & Name \\
\hline Beta-lactam & Amoxicillin & Penicillin-G \\
Fluoroquinolones & Enrofloxacin & Ofloxacin \\
Sulfonamides & Sulfadiazine & Sulfamethazine Sulfamethoxa-zole \\
Macrolides & Erythromycin & \\
Tetracyclines & Chlortetracycline & Oxytetracycline \\
Other antibiotics & Chloramphenicol & \\
& & \\
Anticonvulsants & Carbamazepine & Primidone \\
\hline
\end{tabular}




\subsection{Kinetic Modeling}

Both the pseudo-first order and pseudo-second order kinetics models were used to fit the experimental data. The equation for the pseudo-first order model is as follows [8]:

$$
\mathrm{d} q_{t} / \mathrm{d} t=k_{1}\left(q_{e}-q_{t}\right)
$$

where $q_{e}$ and $q_{t}$ are the sorption capacities $\left(\mathrm{mg} \cdot \mathrm{g}^{-1}\right)$ at equilibrium and at time $t$, respectively, and $\mathrm{k}_{1}$ is the rate constant of the pseudo-first order sorption $\left(\mathrm{L} \cdot \mathrm{hr}^{-1}\right)$. Integrating (1) from $\mathrm{t}=$ 0 to $\mathrm{t}$ and $q_{t}=0$ to $q_{t}$ yields:

$$
\log \left(q_{e}-q_{t}\right)=\log q_{e}-k_{1} t
$$

If pseudo-first order kinetics is applicable, then a plot of $\log \left(q_{e}-q_{t}\right)$ vs. $t$ should yield a straight line and the slope corresponds to $k_{1}$. Here the sorption capacities determined at 48 hours were used as $q_{e}$.

The equation for the pseudo-second order model is written as follows [9]:

$$
\mathrm{d} q_{t} / \mathrm{d} t=k_{2}\left(q_{e}-q_{t}\right)^{2}
$$

where $\mathrm{k}_{2}$ is the rate constant of the pseudo-second order sorption ( $\mathrm{g} \cdot \mathrm{mg}^{-1} \cdot \mathrm{hr}^{-1}$ ). Integrating (3) from $t=0$ to $t$ and $q_{t}=0$ to $q_{t}$ yields:

$$
1 /\left(q_{e}-q_{t}\right)=1 / q_{e}+k_{2} t
$$

Rearranging (4) gives the linearized form:

$$
t / q_{t}=1 /\left(k_{2} q_{e}^{2}\right)+t / q_{e}
$$

If pseudo-second order kinetics is applicable, a plot of $t / q_{t}$ vs. $t$ should give a straight line, from which $q_{e}$ and $k_{2}$ and can be determined from the slope and intercept of the line.

\section{Results and Discussion}

The pseudo-first order kinetics model did not fit the data well (plots not shown), whereas the pseudo-second order kinetics model yielded excellent fits for all compounds (Figure 1, $\mathrm{r}^{2}>$ 0.996), suggesting a chemical adsorption process rather than a physical adsorption process.

The fitted $q_{e}$ and $\mathrm{k}_{2}$ values are listed in Table 2. Chlortetracycline, carbamazepine, oxytetracycline, and enrofloxacin appear to have the highest pseudo-second order rate constants

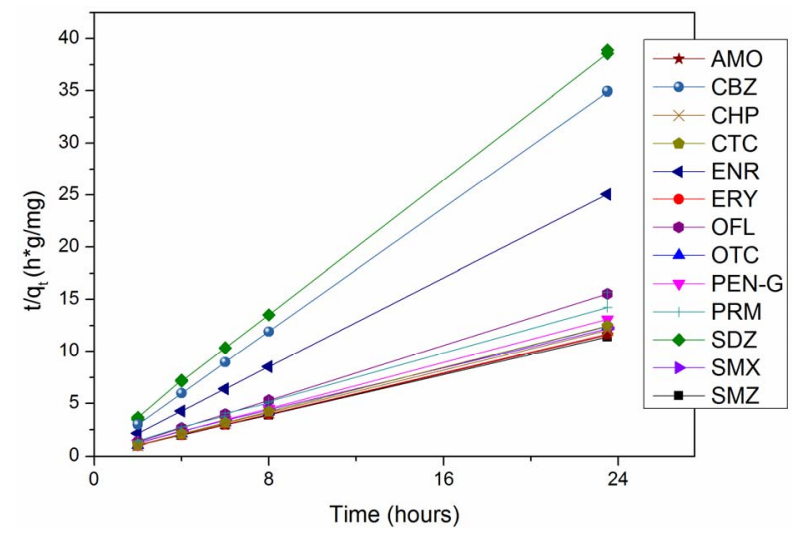

Figure 1. A plot of $t / q_{t}$ vs. $t$ according to (5). Straight lines represent the best fits. All $\mathbf{r}^{2}$ values of the fits are greater than 0.996 .
Table 2. Fitted parameter values from the Pseudo-second order kinetics model.

\begin{tabular}{lcc}
\hline \multicolumn{1}{c}{ Pharmaceuticals } & $\mathbf{q}_{\mathbf{e}}\left(\mathbf{m g} \cdot \mathbf{g}^{-\mathbf{1}}\right)$ & $\mathbf{k}_{\mathbf{2}}\left(\mathbf{g}^{\left.\mathbf{m} \mathbf{g}^{-\mathbf{1}} \cdot \mathbf{h} \mathbf{r}^{-\mathbf{1}}\right)}\right.$ \\
\hline Amoxicillin (AMO) & 2.04 & 7.19 \\
Carbamazepine (CAB) & 0.67 & 52.05 \\
Chloramphenicol (CHP) & 1.95 & 7.36 \\
Chlortetracycline (CTC) & 1.69 & 94.98 \\
Enrofloxacin (ENR) & 0.94 & 45.09 \\
Erythromycin (ERY) & 2.01 & 31.68 \\
Ofloxacin (OFL) & 1.51 & 17.33 \\
Oxytetracycline (OTC) & 1.89 & 45.68 \\
Penicillin-G (PEN-G) & 1.81 & 2.68 \\
Primidone (PRM) & 1.59 & 2.57 \\
Sulfadiazine (SDZ) & 0.61 & 5.15 \\
Sulfamethazine (SMZ) & 2.07 & 4.96 \\
Sulfamethoxazole (SMX) & 1.96 & 0.95 \\
SUM & 20.75 & \\
\hline
\end{tabular}

(>45 g. $\mathrm{mg}^{-1} \cdot \mathrm{hr}^{-1}$ ), whereas penicillin-G, primidone, and sulfamethoxazole seem to have the lowest rate constants $(<3$ $\mathrm{g} \cdot \mathrm{mg}^{-1} \cdot \mathrm{hr}^{-1}$, Table 2).

Based on the kinetics experiments performed here, most of the compounds have equilibrium sorption capacities around 2 $\mathrm{mg} \cdot \mathrm{g}^{-1}$, whereas carbamazepine and sulfadiazine have lower capacities (around $0.6 \mathrm{mg} \cdot \mathrm{g}^{-1}$ ). The total sorption capacity (sum of all compounds) is around $21 \mathrm{mg} \cdot \mathrm{g}^{-1}$. The total capacity determined here, however, is an order of magnitude lower than that determined by equilibrium adsorption experiments with higher contaminant loadings [6].

\section{Acknowledgements}

This work was partially supported by a STAR grant from the United States Environmental Protection Agency (US EPA, RD835178). Any opinions, findings, and conclusions or recommendations expressed in this material are those of the authors and do not necessarily reflect the views of the US EPA. R. Ding would like to acknowledge a graduate fellowship from the Office of the Dean of Science.

\section{REFERENCES}

[1] R. Wise, “Antimicrobial resistance: priorities for action," J. Antimicrob. Chemoth. Vol. 49, pp. 585-586, 2002.

[2] A.B.A. Boxall, D.W. Kolpin, B. Halling-Sorensen, and J.Tolls, “Are veterinary medicines causing environmental risks?” Environ. Sci. Technol. Vol. 37, pp. 286A-294A, 2003.

[3] A.K. Sarmah, M.T. Meyer, and A.B.A. Boxall, "A global perpective on the use, sales, exposure pathways, occurrence, fate and effects of veterinary antibiotics (VAs) in the environment," Chemosphere Vol. 65, pp. 725-729, 2006. 
[4] R. Hirsch, T. Ternes, K. Haberer and K.L. Kratz, "Occurrence of antibiotics in the aquatic environment," Sci. Total Environ. Vol. 225, pp. 109-118, 1999.

[5] N. Kemper, "Veterinary antibiotics in the aquatic and terrestrial environment,” Ecol. Indi. Vol. 8, pp. 1-13, 2008.

[6] R. Ding, P. Zhang, M. Seredych, and T.J. Bandosz, "Removal of antibiotics from water using sewage sludge and waste oil sludge derived adsorbents,"

Water Res.

DOI: 10.1016/j.bbr.2011.03.031, in press.

[7] J. Rivera-Utrilla, G. Prados-Joya, M. Sanchez-Polo, M.A.
Ferro-Garcia and I. Bautista-Toledo, "Removal of nitroimidazole antibiotics from aqueous solution by adsorption/bioadsorption on activated carbon,” J. Hazard. Mater. Vol. 170, pp. 298-305, 2009.

[8] S. Lagergren, "About the theory of so-called adsorption of solution substances. kunglia srenska vertens Ka psakademiens," Handlinger Vol. 24, pp. 147-156, 1898.

[9] Y. S. Ho, G. Mckay. "A. two stage batch sorption optimized design for dye removal to minimize contact time,” Trans. IChem. E. Vol. 76, pp. 313-318, 1998. 